\title{
ANALISIS OPTIMASI PENEMPATAN KAPASITOR BANK PADA JARINGAN TEGANGAN MENENGAH 20KV FEEDER IS03 RAYON LIMBOTO UNTUK MEMPERBAIKI KUALITAS TEGANGAN
}

\author{
Christopher Elchrisa Uno ${ }^{1}$, L.M. Kamil Amali ${ }^{2}$, Ade Irawaty Tolago ${ }^{3}$ \\ ${ }^{123}$ Prodi Teknik Elektro, Fakultas Teknik, Universitas Negeri Gorontalo \\ Jl. Jend. Sudirman No.6 Kota Gorontalo 96128 Indonesia \\ chris_1195@yahoo.co.id, kamilamali@ung.ac.id, adeirawty75@ung.ac.id
}

\begin{abstract}
ABSTRAK
Kapasitor bank memberikan manfaat dalam proses kinerja sistem distribusi dimana kapasitor bank dapat mengurangi losses, memperbesar kapasitas layanan dan mengurangi jatuh tegangan. Penempatan kapasitor bank diperlukan untuk menanggulangi permasalahan jatuh tegangan yang terjadi baik pada saluran transmisi bertegangan tinggi maupun saluran distribusi tegangan menengah. Penelitian mengenai Analisa Optimasi Penempatan Kapasitor Bank Pada Jaringan Tegangan Menengah 20 kV Feeder IS.03 Rayon Limboto Untuk Memperbaiki Kualitas Tegangan ini dilakukan dengan tujuan mendapatkan lokasi optimal dan rating kapasitor bank pada penyulang IS.03. Adapun metode yang digunakan dalam penelitian ini yaitu metode simulasi dimana metode simulasi merupakan bentuk penelitian yang bertujuan untuk mencari gambaran melalui sebuah sistem berskala kecil atau sederhana (model) dimana didalam model tersebut akan dilakukan manipulasi atau kontrol untuk melihat pengaruhnya. Berdasarkan hasil analisa dan pembahasan yang telah dilakukan pada penyulang IS.03 didapatkan kondisi paling optimum dengan jumlah kapasitor bank sebesar 6 x $150 \mathrm{kVAr}$ dimana rata-rata selisih kenaikan tegangan ujung penyulang setelah pemasangan kapasitor bank sebesar $0.903 \mathrm{kV}$ pada 3 (tiga) penyulang percabangan yaitu LI.03, LY.01, dan LY.02 yang mengalami jatuh tegangan melewati batas standar yang telah ditentukan.
\end{abstract}

Kata Kunci : Sistem Distribusi, Kapasitor, Rugi Daya, Tegangan Jatuh.

\section{PENDAHULUAN}

Peningkatan mutu pendistribusian tenaga listrik merupakan salah satu unsur penting dalam upaya meningkatkan pelayanan terhadap masyarakat dan memenuhi kebutuhan energi listrik yang tumbuh cukup pesat. Perencanaan merupakan hal yang dibutuhkan untuk menjamin sebuah energi listrik yang berkelanjutan atau terjaga keberlangsungannya. Hal - hal yang perlu diperhatikan dalam menjaga keberlangsungan pasokan energi listrik ke konsumen dalam hal ini masyarakat adalah dengan mempertimbangkan nilai frekuensi, sudut daya, dan kestabilan tegangan sehingga pendistribusian energi dapat berlangsung secara optimal. Oleh karena itu, dibutuhkan sebuah sistem tenaga listrik yang terencana dengan baik sehingga dapat melayani beban secara berkelanjutan. 
Salah satu bentuk gangguan dalam sistem tenaga listrik adalah adanya drop tegangan, hal ini diakibatkan oleh beberapa sebab antara lain adalah jarak tempuh antara pusat listrik ke pusat beban yang cukup jauh, dan beban yang cukup besar sehingga tegangan pada ujung saluran mengalami penurunan. Akibat dari drop tegangan ini dapat mengganggu kinerja dan keamanan alat-alat elektronik yang ada di rumah-rumah pelanggan. Nilai toleransi jatuh tegangan yang diatur dalam SPLN adalah senilai $+5 \%$ dan $-10 \%$ untuk jaringan distribusi dengan nominal tegangan $20 \mathrm{kV}$. Oleh sebab itu, nilai tegangan yang ada pada ujung saluran harus diperhatikan karena dapat memungkinkan munculnya gangguangangguan pada pihak konsumen. (SPLN 1/1995)

Dengan luasan wilayah provinsi Gorontalo, tentunya juga menghadapi permasalahan yang sama mengenai tingkat kestabilan tegangan dalam penyaluran energi listrik. Perlu dilakukan studi yang membahas mengenai solusi untuk permasalahan jatuh tegangan pada salah satu penyulang yang ada di provinsi Gorontalo. Penyulang atau Feeder IS03 yang terdapat pada GI Isimu Rayon Limboto merupakan salah satu penyulang yang mengalami Drop Voltage yang cukup besar sehingga butuh dilakukan upaya untuk segera memperbaiki kestabilan tegangan yang ada sepanjang saluran penyulang IS03 terutama ptegangan ujung saluran.
Dengan jaringan distribusi dengan panjang saluran mencapai $298.06 \mathrm{kms}$ merupakan penyulang terpanjang yang ada di Gorontalo dan pembebanan yang angkanya hingga mencapai $84.92 \%$, hal ini memunginkan munculnya permasalahan dalam penyaluran tegangan hingga ke ujung saluran. Pada tahun 2015 nilai tegangan pangkal pada penyulang ini adalah $20.43 \mathrm{kV}$ dengan tegangan ujungnya adalah $16.27 \mathrm{kV}$ dimana persentase jatuh tegangannya mencapai $18.65 \%$ dari tegangan nominal.

\section{METODE PENELITIAN}

Adapun metode yang digunakan dalam penelitian antara lain adalah Metode Simulasi dan Studi Kasus. Simulasi merupakan bentuk penelitian yang bertujuan untuk mencari gambaran melalui sebuah sistem berskala kecil atau sederhana (model) dimana didalam model tersebut akan dilakukan manipulasi atau kontrol untuk melihat pengaruhnya. Studi Kasus adalah eksplorasi mendalam dari sistem terikat berdasarkan pegumpulan data yang luas. Studi kasus melibatkan investigasi kasus yang dapat didefinisikan sebagai suatu entitas atau objek studi yang dibatasi, atau terpisah untuk penelitian dalam hal waktu, tempat atau batas- batas fisik.

\section{Tahapan Penelitian}

Langkah - langkah yang akan diambil dalam melakukan penelitian ini adalah: 
1. Melakukan studi literatur yang akan digunakan sebagai bahan acuan dalam penelitan. Pengumpulan data yang dilakukan dalam penelitian ini adalah berupa data - data yang bersumber dari PT PLN (Persero) Area Gorontalo.

2. Membuat single line diagram untuk penyulang IS03 pada aplikasi ETAP 12.6.0.

3. Memasukkan data-data pada penyulang IS03 yang telah dikumpulkan untuk digunakan dalam simulasi.

4. Menjalankan simulasi ETAP 12.6.0

5. Mengamati hasil running simulasi, apakah sudah benar atau masih terdapat kesalahan atau error dalam penginputan data.

6. Apabila sudah benar, maka dilakukan pengamatan terhadap bus yang mengalami penurunan tegangan dibawah batas minimal yang diperbolehkan.

7. Menjalankan simulasi penempatan optimal kapasitor yang terdapat dalam ETAP 12.6.0.

8. Menjalankan kembali Load Flow Analysis dan memperhatikan hasil aliran daya saat sebelum dan sesudah pemasangan kapasitor bank.

HASIL DAN PEMBAHASAN Karakteristik Tegangan Penyulang IS.03
Berdasarkan hasil simulasi aliran beban pada penyulang IS.03, Tabel 1 menunjukkan karakteristik tegangan pangkal dan tegangan ujung pada penyulang IS.03 sistem distribusi tegangan menengah $20 \mathrm{kV}$.

Tabel 1 Karakteristik tegangan pada penyulang IS.03

\begin{tabular}{|c|c|c|c|c|}
\hline & FEEDER & $\begin{array}{c}\text { Teg. } \\
\text { Nominal } \\
(\mathrm{kV})\end{array}$ & $\begin{array}{c}\text { Teg. } \\
\text { Pangkal } \\
(\mathrm{kV})\end{array}$ & $\begin{array}{c}\text { Teg. } \\
\text { Ujung } \\
(\mathrm{kV})\end{array}$ \\
\hline GI IIIMU & IS.03 & 20 & 19.86 & 19.49 \\
\hline GHISIMU & LI.03 & 20 & 19.49 & 17.14 \\
\hline $\begin{array}{c}\text { GH } \\
\text { PAGUYAMAN }\end{array}$ & LY.01 & 20 & 17.177 & 17.126 \\
\cline { 2 - 5 } & LY.02 & 20 & 17.177 & 16.704 \\
\hline $\begin{array}{c}\text { RECLOSER } \\
\text { SIDO }\end{array}$ & LY.03 & 20 & 18.247 & 17.994 \\
\hline
\end{tabular}

Tabel 1 diatas memperlihatkan bahwa kondisi tegangan yang terdapat pada penyulang IS.03 mengalami penurunan pada beberapa titik. Adapun bentuk grafis perbandingan antara tegangan pangkal dan tegangan ujung masing - masing penyulang ditunjukkan pada Gambar 1.

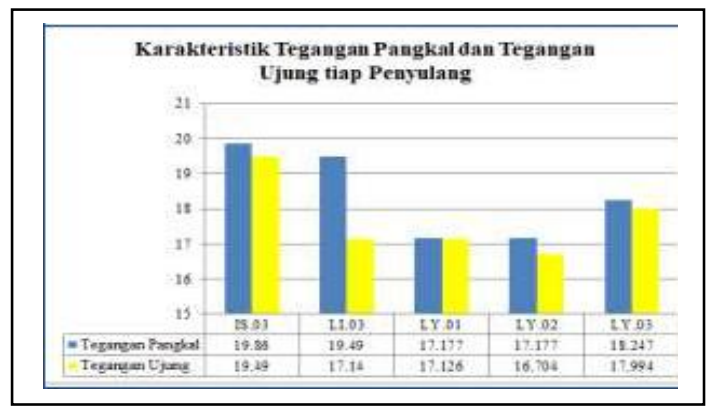

Gambar 1. Grafik karakteristik tegangan pangkal dan tegangan ujung tia penyulang

Grafik 1 menunjukkan perbandingan antara tegangan pangkal dan tegangan ujung pada tiap penyulang. Tegangan pada beberapa penyulang mengalami penurunan 
melewati standar tegangan yang telah ditentukan oleh pihak PLN.

\section{Perhitungan Rating Kapasitor dan Jarak Optimal Penempatan Kapasitor Bank}

Rating dan jarak optimal kapasitor bank ditentukan melalui perhitungan yang dilakukan berdasarkan hasil simulasi yang telah dilakukan sebelumnya dengan mempertimbangkan jumlah daya keseluruhan pada sistem dan panjang total penyulang. Penghitungan rating dan jarak kapasitor bank dibuat 4 kondisi.

1. Kondisi 1; Pada kondisi ini jumlah kapasitor yang diberikan sejumlah 6 unit dengan kapasitas kapasitornya sebesar 150 kVAr per kapasitor.

2. Kondisi 2; Pada kondisi ini jumlah kapasitor yang diberikan sejumlah 5 unit dengan kapasitas kapasitornya sebesar 170 kVAr per kapasitor

3. Kondisi 3; Pada kondisi ini jumlah kapasitor yang diberikan sejumlah 4 unit dengan kapasitas kapasitornya sebesar 200 kVAr per kapasitor.

4. Kondisi 4; Pada kondisi ini jumlah kapasitor yang diberikan adalah sejumlah 3 unit dengan kapasitas kapasitornya sebesar 290 kVAr per kapasitor.

\section{Hasil Perhitungan Rating Kapasitor dan Jarak Optimal Penempatan Kapasitor Bank}

Setelah dilakukan penempatan kapasitor bank pada jaringan penyulang IS.03 maka dilakukan simulasi untuk mengetahui pengaruh dari kapasitor yang telah dipasang terhadap nilai tegangan pada jaringan distribusi penyulang IS.03. Hasilnya dapat dilihat pada Gambar 2 dan Gambar 3.

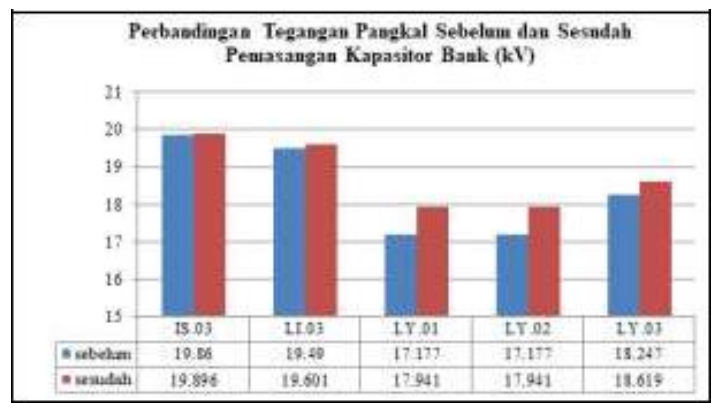

Gambar 2. Grafik perbandingan tegangan pada tiap pangkal penyulang

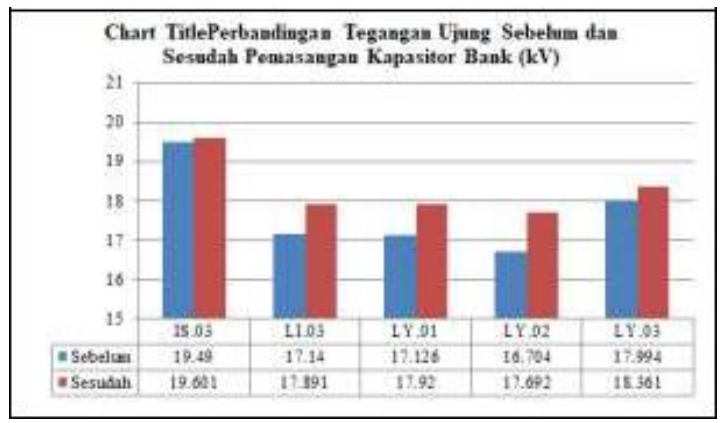

Gambar 3. Grafik perbandingan tegangan pada tiap ujung penyulang

Perhitungan dengan cara yang sama dilakukan untuk mendapatka lokasi penempatan kapasitor bank pada kondisi 2 sampai kondisi 4. Setelah dilakukan perhitungan maka dilakukan simulasi untuk mendapatkan nilai tegangan pangkal dan tegangan ujung setelah ditempatkan kapasitor bank.

Representasi dari keempat kondisi dengan menggunakan metode seperti pada persamaan 4 dapat ditinjau pada tabel 2 berikut.

Tabel 2. Perbandingan profil tegangan ujung dan susut jaringan 


\begin{tabular}{|c|c|c|c|c|c|c|}
\hline \multirow{2}{*}{ SKENARIO } & \multicolumn{5}{|c|}{ Tegangan Ujung Peayulang (kV) } & \multirow{2}{*}{$\begin{array}{l}\text { Susut } \\
\text { Daya } \\
\text { Alctif }(\%)\end{array}$} \\
\hline & Is..03 & L.03 & LY.01 & LY.02 & LY. 03 & \\
\hline Kondisi 1 & 19,6 & 17,941 & 17,92 & 17,692 & 18,361 & 9,33 \\
\hline Kondisi 2 & 19.59 & 17,887 & 17,92 & 17,547 & 18,345 & 9,31 \\
\hline Kondisi 3 & 19,589 & 17,832 & 17,845 & 17,518 & 18,32 & 9,28 \\
\hline Kondisi 4 & 19.597 & 17,894 & 17.886 & 17,607 & 18,361 & 9,31 \\
\hline
\end{tabular}

Berdasarkan tabel 2 diatas, dapat diamati

kondisi tegangan pada tiap - tiap penyulang setelah dilakukan penempatan optimal kapasitor bank untuk keempat kondisi. Tiap kondisi diberikan jumlah kapasitor yang berbeda. Kondisi 1 memiliki 6 unit kapasitor bank dengan daya reaktif $150 \mathrm{kVAr}$, kondisi 2 memiliki 5 unit kapasitor bank dengan daya reaktif $170 \mathrm{kVAr}$, kondisi 3 memiliki 4 unit kapasitor bank dengan daya kVAr $200 \mathrm{kVAr}$, dan kondisi 4 memiliki 3 unit kapasitor bank dengan daya reaktif $290 \mathrm{kVAr}$.

Setiap kondisi memberikan hasil perbaikan pada tegangan ujung yang cukup signifikan. Susut daya aktif pada tiap kondisi juga berbeda-beda berkisar antara 9,28\% 9,33\%. Dari keempat kondisi diatas, didapatkan bahwa kondisi dengan penempatan kapasitor bank paling optimal dilihat dari perbaikan tegangan ujung adalah kondisi 1 .

Sedangkan kondisi dengan penempatan kapasitor bank paling optimal dilihat dari persentase susut daya aktif adalah kondisi 3 .

\section{KESIMPULAN}

Berdasarkan hasil penelitian yang telah dilakukan dengan menggunakan program ETAP, maka dapat disimpulkan :

1. Hasil analisa terkait lokasi penempatan optimal kapasitor bank dibagi dalam 4 (empat) kondisi dengan jumlah kapasitor dan jarak yang berbeda serta rating kapasitor untuk masing-masing kondisi adalah sebesar $150 \mathrm{kVAr}, 170 \mathrm{kVAr}, 200$ kVAr, dan $290 \mathrm{kVAr}$.

2. Daya aktif yang disalurkan sistem sebelum penempatan kapasitor bank adalah sebesar 3.047 MW dengan susut daya aktif sebesar 0.291 MW dimana nilai persentasinya mencapai $9,55 \%$. Berdasarkan simulasi keempat kondisi, nilai susut sistem yang paling rendah ditunjukkan pada kondisi 3 (tiga) dengan persentase nilai susut daya aktif sebesar $9,28 \%$.

3. Kondisi dengan profil tegangan setelah pemasangan kapasitor bank paling baik adalah kondisi 1. Maka kondisi ini dijadikan sebagai perbandingan antara tegangan sebelum dan tegangan setelah pemasangan kapasitor bank

\section{Saran}

Setelah melakukan penelitian diatas, penulis menyarankan beberapa hal berdasarkan hasil yang didapatkan.

- Penggunaan kapasitor bank pada penyulang IS.03 merupakan salah satu solusi yang dapat ditawarkan untuk menanggulangi masalah jatuh tegangan pada sistem distribusi tersebut. Namun terdapat pula beberapa solusi untuk menanggulangi permasalahan ini, antara lain adalah pembangunan Gardu Induk di daerah dekat dengan ujung penyulang. Pembangunan Gardu Induk baru dapat menunjang penyaluran daya listrik yang lebih baik terhadap pelanggan dan dapat 
menjaga kestabilan tegangan pada daerah sekitar GI tersebut.

- Penelitian yang dilakukan dengan menggunakan aplikasi ETAP kedepannya agar dapat dibandingkan dengan aplikasi serupa ataupun metode lain untuk bisa mendapatkan hasil yang lebih akurat agar penempatan kapasitor bank dapat lebih optimal.

- Metode penempatan optimal kapasitor bank dapat dikembangkan dengan mempertimbangakan faktor-faktor tertentu antara lain adalah penempatan kapasitor bank pada jaringan sistem distribusi yang tidak seimbang.

- Pertumbuhan beban merupakan salah satu faktor yang perlu diperhatikan dalam menanggulangi masalah jatuh tegangan. Oleh karena itu, diperlukan studi lebih lanjut mengenai keadaan sistem apabila terdapat fluktuasi beban secara drastis pada sistem ini.

\section{DAFTAR PUSTAKA}

[1] Tampubolon, David. dkk, 2009. Optimalisasi Penggunaan Kapasitor Bank pada Jaringan $20 \mathrm{kV}$ dengan Simulasi ETAP (Studi Kasus pada Feeder Srikandi di PLN Rayon Pangkala Balai, Wilayah SumateraSelatan).Jurnal. Universitas Sumatera Selatan. Sumatera Selatan.

[2] PT. PLN. Master Plan Sistem Distribusi Tenaga Listrik Tahun 2016 $-2020$.

[3] Erviana, Mira. dkk, 2012. Optimasi Penempatan dan Kapasitas Kapasitor Bank pada Sistem Distribusi untuk Mereduksi Rugi Daya Menggunakan
Particle Swarm Optimization. Jurnal. Universitas Diponegoro. Semarang.

[4] Habsoro, S.W. dkk. 2012. Analisa Penempatan Kapasitor Bank untuk Perhitungan Drop Voltage pada Feeder Batang 02 Tahun 2012-2016 dengan Software ETAP 7.0.0 . Jurnal. Universitas Diponegoro. Semarang.

[5] Abidin, Putra. 2014. Penempatan Optimal Kapasitor Bank pada Jaringan Disrtibusi $20 \mathrm{kV}$ Rayon Bangkiang untuk Mengurangi Penurunan Tegangan Menggunakan ETAP 7.5.0. Tugas Akhir. Universitas Islam Negeri Sultas Syarif Kasim Riau. Pekanbaru.

[6] Tanjung, Abrar. 2012. Analisa Sistem Distribusi $20 \mathrm{kV}$ untuk Memperbaiki Kinerja dan Keandalan Sistem Distribusi Menggunakan Electrical Transient Analisys Program. Jurnal. Universitas Lancang Kuning.

[7] Anderso, P.M., Fouad, A.A., 1982. Power System Control and Stability. The Iowa State University Press.

[8] SPLN 1:1978 Tegangan tegangan Standar Variasi Tegangan Pelayanan.

[9] Sanatang. Perbaikan Stabilitas Frekuensi dan Tegangan pada Beban Dinamik Sistem SULSELBAR Menggunakan Metode Linear Quadratic Regulator (LQR). Jurnal. Universitas Negeri Makassar. Makassar.

[10] Suswanto, Danang. Klasifikasi Jaringan Distribusi. Buku Ajar BAB II. 